\title{
Early effects of copper accumulation on methionine metabolism.
}

Miguel Delgado ${ }^{1}$, Juliana Pérez-Miguelsanz ${ }^{2}$, Francisco Garrido ${ }^{1}$, Gemma RodríguezTarduchy ${ }^{1}$, Dolores Pérez-Sala ${ }^{3}$ and María A. Pajares ${ }^{1, *}$

${ }^{1}$ Instituto de Investigaciones Biomédicas Alberto Sols (CSIC-UAM), Arturo Duperier 4, 28029 Madrid, Spain

${ }^{2}$ Departmento de Anatomía y Embriología Humana I, Facultad de Medicina, Universidad Complutense de Madrid, Plaza de Ramón y Cajal s/n, 28040 Madrid, Spain.

${ }^{3}$ Centro de Investigaciones Biológicas (CSIC), Ramiro de Maeztu 9, 28040 Madrid, Spain

*To whom correspondence should be addressed at: Instituto de Investigaciones Biomédicas Alberto Sols (CSIC-UAM), Arturo Duperier 4, 28029 Madrid, Spain (Phone: 34-915854414; FAX: 34-915854010; email: mapajares@iib.uam.es)

Running title: Copper accumulation and methionine cycle 


\begin{abstract}
Wilson's disease is characterized by long-term hepatic accumulation of copper leading to liver disease with reduction of S-adenosylmethionine synthesis. However, the initial changes in this pathway remain unknown and constitute the objective of the present study. Using the Long Evans Cinnamon rat model early alterations in the mRNA and protein levels, as well as in the activities of several enzymes of the methionine cycle were detected. Noteworthy, the main change was a redox mediated $80 \%$ decrease in the mRNA levels of the methionine adenosyltransferase regulatory subunit as compared to the control group. Moreover, changes in S-adenosylmethionine, S-adenosylhomocysteine, methionine and glutathione levels were also observed. In addition, in vitro experiments show that copper affects the activity and folding of methionine adenosyltransferase catalytic subunits. Taken together, these observations indicate that early copper accumulation alters methionine metabolism with a pattern distinct from that described previously for other liver diseases.
\end{abstract}

Keywords: Methionine metabolism, methionine adenosyltransferase, copper accumulation, Wilson's disease, S-adenosylhomocysteine hydrolase, glutathione. 


\section{INTRODUCTION}

The liver exerts a central role in methionine metabolism [1] and copper homeostasis [2]. This metal ion appears bound to glutathione, amino acids, transport or storage proteins and as an essential cofactor to many enzymes [3]. Transport of copper is mediated by several proteins, including: ATP7A, CTR1 and ATP7B [3]. ATP7A controls passage of copper from the intestinal cells into the portal circulation, and its absence causes Menkes' disease [4]. The CTR1 transporter takes copper from the carriers in the portal circulation into the hepatocyte [5], where the metal is rapidly routed to copper metallochaperones of the cytosol, mitochondria and secretory pathways $[3,6]$. On the other hand, ATP7B is involved in copper transference to the bile (1.5 $\mathrm{mg} /$ day in humans), the major route for excretion, and a critical process in maintaining the hepatic concentration of the metal [2]. For this purpose, copper-loaded ATP7B translocates from the trans-Golgi network to the vesicular compartment. Either the absence or a reduced activity of this transporter leads to hepatic copper accumulation that results in Wilson's disease [7].

Liver is also the site for early copper accumulation in pathological processes. Normal copper levels $(10-100 \mu \mathrm{M})$ [3] can increase up to 30-50 times at early stages of Wilson's disease with little clinical manifestations [7]. Long Evans Cinnamon rats (LEC) have been extensively used as a model for studies of this pathology $[8,9]$ due to the similarities observed in clinical and biochemical features. The presence of genetic defects affecting the $A T P 7 B$ gene are the cause of the disease in either humans or animal models, but the anomalies detected are not identical. LEC rats present a $900 \mathrm{bp}$ deletion in the coding region of the $A T P 7 B$ gene [10], whereas the most frequently reported mutation in Wilson's disease patients is the H1069Q substitution [7]. LEC rats suffer acute hepatitis at 8-12 weeks of age and a large incidence of death between 17-20 
weeks. Survivors develop cirrhosis and are highly susceptible to hepatocellular carcinoma (HCC), two manifestations of hepatic disease in which impairment of methionine metabolism has been reported in animal models and human samples of other etiologies [11-13].

Three MAT genes exist in mammals, MAT1A, MAT2A and MAT2B. Catalytic subunits, MAT $\alpha 1$ and MAT $\alpha 2$, are codified by $M A T 1 A$ and $M A T 2 A$, respectively, whereas the product of the MAT2B gene is the regulatory $\beta$ subunit [1]. MAT $\alpha 1$ subunits associate to render homodimers (MAT III) and homotetramers (MAT I) that differ in their affinity for methionine, and constitute the main hepatic isoenzymes under normal conditions. On the other hand, MAT $\alpha 2$ and $\beta$ subunits form hetero-oligomers that constitute the main fetal and cancer related isoenzyme (MAT II). Impairment of the methionine cycle during pathologic processes includes decreases in total MAT activity, switches in the levels of MAT mRNAs [14], and changes in the ratio of the homooligomers MAT I and III [15]. Moreover, MAT1A knockout mice show reduced Sadenosylmethionine (AdoMet) levels and develop HCC spontaneously [16], whereas AdoMet treatment in animal models of liver injury has been reported be hepatoprotective [17]. These data suggest the existence of a direct link between several hepatic pathological processes and methionine metabolism. In addition, another enzyme of this pathway, S-adenosylhomocysteine hydrolase (SAHH) has been shown to bind $\left(\mathrm{Kd} \sim 10^{-11} \mathrm{M}\right)$ and to be inactivated by copper $\left(\mathrm{K}_{\mathrm{i}} 14 \mathrm{nM}\right)[18]$. In spite of all these data, potential alterations in the methionine cycle due to copper accumulation have not been explored, except for a measurement of MAT activity and AdoMet levels in LEC rats at late phases of the disease (29 and 42 weeks) [19]. Thus, the purpose of this work was to get insight into the changes in the hepatic methionine cycle at early stages of 
copper accumulation to decipher the events involved in the development of this pathology. 


\section{MATERIALS AND METHODS}

2.1 Animals and tissue extraction. Long Evans (LE) and Long Evans Cinnamon (LEC) rats 9 weeks old were purchased through Charles River Laboratories España (Barcelona, Spain). All animals were treated according to the Guidelines for Animal Experimentation of the CSIC and the European Union. Tissues were extracted immediately after animal death, placed on liquid nitrogen and stored at $-80^{\circ} \mathrm{C}$.

2.2 Histology. Rat liver portions were embedded in paraffin after formaldehyde fixation and dehydration. Sections (10 microns) were prepared and morphological analysis carried out after paraffin elimination and rehydration followed by hematoxilineosin staining. The method of Jain et al. [20] with slight modifications was used for identification of copper deposits. Briefly, sections were stained with a mixture of $0.1 \%$ rubeanic acid in ethanol 1:20(v/v) and $10 \%$ sodium acetate overnight at $37^{\circ} \mathrm{C}$, cleared in ethanol and xylene. In addition, iron deposits were visualized by Perls' stain [21]. Briefly, sections were immersed in a mixture of $10 \%$ potassium ferrocyanide and $2 \%$ hydrochloric acid 1:1 (v/v) for $10 \mathrm{~min}$, cleared with water and counterstained with nuclear red. Finally, sections were dehydrated and coverslip mounted with Eukit (Sigma Chemical Co, St. Louis) for observation with a Leica DMR Microscope equipped with a Leica DFC 320 video camera connected to a Fujitsu Celeron computer. Standard digital image capture was obtained using an Adobe Photoshop CS 8.0 image capture card.

2.3 Cell treatments. Hepatoma $\mathrm{H} 35$ cells at $80 \%$ confluence were treated with 1 $\mathrm{mM} \mathrm{CuSO}_{4}, 5 \mathrm{mM} \mathrm{N}$-acetylcysteine (NAC), $10 \mu \mathrm{M}$ neocuproine or $1 \mathrm{mM}$ buthionine sulfoximine (BSO) before RNA extraction. Combination of the different treatments was performed by addition of neocuproine 2 hours before copper addition, whereas NAC and BSO were included 8 hours before the metal. Copper incubations were performed for 24 hours. 
2.4 RNA extraction and quantitative RT-PCR. Total RNA was isolated using the Trizol method (Sigma Chemical Co, St. Louis) and quality and quantity determined spectrometrically and by gel electrophoresis. Gene specific primers were designed using the program Primer Express 3.0 (Applied Biosystems, Foster City) with Tm values between $58-60^{\circ} \mathrm{C}$ (Table 1 of supplementary material). Expression of the different mRNAs of our interest was evaluated using the ABI 7900HT Real-Time PCR system (Applied Biosystems). Reverse transcription was done using $1.25 \mu \mathrm{g}$ of total RNA and the High Capacity Archive kit (Applied Biosystems). cDNAs (10 ng) were amplified in triplicate using appropriate primer concentrations (Table 1 of supplementary material) and Power SYBR Green PCR Master Mix (Applied Biosystems) in a total reaction volume of $10 \mu \mathrm{l}$ at the sequencing facilities of the Instituto de Investigaciones Biomédicas Alberto Sols (CSIC-UAM). The thermal protocol included: i) $10 \mathrm{~min}$ denaturation at $95^{\circ} \mathrm{C}$; and ii) $15 \mathrm{~s}$ denaturation at $95^{\circ} \mathrm{C}$ followed by 1 min extension at $60^{\circ} \mathrm{C}$ for 40 cycles. Fluorescent signals were collected after each extension step, and the curves analyzed by the SDS 2.2.2 software. The specificity of the amplification was determined after the last cycle of the PCR reaction by dissociation curve analysis. Relative expression ratios were normalized to the geometric mean of the $18 \mathrm{~S}$ gene used as a control. Experimental efficiencies were calculated for each transcript and used to obtain the fold changes according to Pfaffl et al. [22].

2.5 Preparation of cytosolic fractions and activity measurements. Cytosolic samples were prepared as described previously [23] and used to determine MAT activity with reaction mixtures containing either $5 \mathrm{mM}, 60 \mu \mathrm{M}$ or $60 \mu \mathrm{M}$ methionine plus $10 \%(\mathrm{v} / \mathrm{v})$ DMSO [23]. The same cytosols were used to determine BHMT activity using $75 \mu \mathrm{l}$ of the sample for 2 hours at $37^{\circ} \mathrm{C}$ as described previously [24]. Samples 
from column fractions $(100 \mu \mathrm{l})$ were analyzed for MAT activity using $5 \mathrm{mM}$ methionine.

2.6 Western blot and Dot blot. Cytosolic samples $(25 \mu \mathrm{g})$ were used for immunoblotting [23] with the following antibodies: i) polyclonal anti-MAT antiserum $(1: 10000 \mathrm{v} / \mathrm{v})[25]$; ii) polyclonal anti-BHMT antiserum $(1: 20000 \mathrm{v} / \mathrm{v})[26]$; iii) antiSAHH antiserum $(1: 1000 \mathrm{v} / \mathrm{v})$ kindly provided by Dr. D. Kloor [27]; and iv) monoclonal anti $\alpha$-tubulin antibody (Sigma Chemical Co, St. Louis, 1:500 v/v). Blots $\begin{array}{llllll}\text { were subjected to densitometric scanning using ImageJ v. } & 1.37\end{array}$ (http://rsb.info.nih.gov/ij/) and the values were normalized against the $\alpha$-tubulin control. The lack of commercial antibodies against rat MAT2 $\beta$ and the failure of the anti-human counterpart to recognize the rat protein precluded the analysis of the regulatory subunit. Gel filtration column fractions $(10 \mu \mathrm{l})$ were used for dot blot as previously described [28].

2.7 Gel filtration chromatography. Cytosolic samples $(100 \mu 1)$ were loaded on a Superose 12/10 HR column (GE Healthcare España SA, Barcelona) equilibrated and eluted at $0.3 \mathrm{ml} / \mathrm{min}$ in $50 \mathrm{mM}$ Tris/ $\mathrm{HCl} \mathrm{pH} 8,10 \mathrm{mM} \mathrm{MgSO}_{4}, 1 \mathrm{mM}$ EDTA containing $150 \mathrm{mM} \mathrm{KCl}$. This buffer also included $250 \mu \mathrm{M} \mathrm{CuSO}_{4}$ for the analysis of copper effects on MAT subunit association. In all the cases $210 \mu$ fractions were collected for activity measurements and dot-blot analyses. Molecular weight standards and their elution volume are indicated on the corresponding figure legends.

2.8 Analysis of the redox state of BHMT and MAT. Cytosolic samples (40 $\mu \mathrm{g})$ isolated in the presence of $40 \mathrm{mM}$ iodoacetamide as described by Cumming et al. [29] were loaded on $12 \%$ SDS-PAGE gels under non-reducing conditions. Lanes were excised and incubated with DTT and iodoacetamide before loading on the second 
dimension $12 \%$ SDS-PAGE gel that was transferred to Immobilon membranes (Millipore Corporation, Bedford) and developed as described above.

2.9 MAT refolding and copper effects on activity and structure. Recombinant MAT $\alpha 1$ and MAT 22 subunits were DTT-refolded in the presence or absence of 250 $\mu \mathrm{M} \mathrm{CuSO}{ }_{4}$ as previously described [30]. Copper effects on activity were analyzed using the DTT-refolded proteins $(50 \mu \mathrm{g} / \mathrm{ml})$. For this purpose, the DTT used for refolding was eliminated by dialysis and MAT activity measured in the presence of $0-1 \mathrm{mM} \mathrm{CuSO}_{4}$ using reaction mixtures with or without DTT. Addition of copper was performed using $50 \mathrm{mM}$ Tris $/ \mathrm{HCl} \mathrm{pH} 8$ or $50 \mathrm{mM}$ Tris/HCl, $50 \mathrm{mM}$ Glycine $\mathrm{pH} 8$ buffers as carriers. Inhibition constants were calculated using GraphPad Prism v. 5.0 (GraphPad Software, San Diego). The effect of copper $(250 \mu \mathrm{M})$ on oligomerization was analyzed by gel filtration chromatography and dot blot.

2.10 Analysis of metabolite levels. Quantification of glutathione reduced (GSH) and oxidized forms (GSSG), AdoMet, AdoHcy, methionine and Hcy was performed at OWL Genomics facilities (Derio, Vizcaya, Spain). Briefly, tissue samples were homogenized in $0.4 \mathrm{M}$ perchloric acid and the supernatant used for determination of the GSH and GSSG levels. On the other hand, derivatization using 6-aminoquinolyl-Nhydroxysuccinimidyl carbamate using the AccQ Tag Ultra derivatization kit (Waters, Milford) was performed for AdoMet, AdoHcy, Hcy and methionine measurements. Samples were analyzed at $50^{\circ} \mathrm{C}$ using a $\mathrm{BEH} \mathrm{C} 18$ column (Waters) and a gradient from $0.05 \%$ formic acid:water (buffer A) to $0.05 \%$ formic acid: acetonitrile (buffer B) coupled to ESI detection.

2.11 Statistics. Data are expressed as mean $\pm \mathrm{SD}$, and Student's $\mathrm{t}$ test for unpaired samples was applied for statistical analysis using GraphPad Prism v.5.0 
(GraphPad Software, San Diego). Differences were considered significant when $\mathrm{p}$ $<0.05$. 


\section{RESULTS}

Livers of 9 weeks old LE and LEC rats showed notable differences in size. In fact, the liver weight was $12.09 \pm 0.34 \mathrm{~g}$ and $5.64 \pm 0.59 \mathrm{~g}$ for LE and LEC rats, respectively. Histological analysis of the samples revealed hepatic accumulation of copper and iron in LEC rats, but no signs of hepatitis were visible (Figure 1). Thus, LEC rats show the early symptoms typically described for the presence of the $A T P 7 B$ mutation.

The presence of alterations in the methionine cycle was initially studied by realtime PCR. Changes in mRNA levels for the different enzymes of this pathway were analyzed and normalized against the $18 \mathrm{~S}$ mRNA. PCR amplification showed increases in BHMT and MAT2A transcripts, whereas reductions in the levels for MAT1A, MAT2B, MS and SAHH were concomitantly observed in the LEC group (Figure 2). The most prominent effect was an $80 \%$ decrease in MAT2B expression, whereas changes in MAT1A, MAT2A, MS and SAHH transcript levels ranged from 17-30\% and the slight increase detected for the BHMT transcript was not significant.

We next studied if these changes in mRNA correlate with alterations at the protein level. For this purpose, western blots of the samples were carried out using the available anti-MAT I/III, anti-BHMT and anti-SAHH antibodies. The results showed $\sim 30 \%$ reductions in the amount of MAT I/III and SAHH proteins in the LEC group, whereas no variation in BHMT protein levels was detected (Figure 3). These data were in good agreement with the changes observed in mRNA.

Alterations in the amount of protein could be reflected in enzyme activities, and hence in the levels of the different metabolites of this pathway. Measurements of the levels for AdoMet, AdoHcy, Hcy and methionine were carried out in samples of both animal groups (Table 1). The results in the LEC group indicate reductions in AdoHcy 
levels and a tendency of AdoMet levels to decrease. In addition, no changes were observed in Hcy concentrations, although a significant increase in methionine levels was observed. Additionally, glutathione levels were also measured in these samples. The data indicate a $\sim 30 \%$ decrease in GSH and a tendency of GSSG concentrations to enhance. Thus, the net result is an apparent increase in the methylation index (AdoMet/AdoHcy) and a decrease in the GSH/GSSG ratio in the LEC group.

The low amount of tissue available forced a restriction of the analysis of enzymatic activities to those of BHMT and MAT that could be carried out with the same sample preparations. No changes in methionine synthesis by BHMT were detected, whereas alterations in MAT activity were observed in LEC rats (Table 2). Differences in methionine affinity, along with the DMSO stimulatory capacity for MAT III have been traditionally used to distinguish among MAT isoenzymes. Thus, we performed measurements of MAT activity at different methionine concentrations and in combination with DMSO. A $30 \%$ reduction in total activity (MAT I + MAT II + MAT III) was detected at $5 \mathrm{mM}$ methionine, whereas a $17 \%$ increase was observed when methionine was used at $60 \mu \mathrm{M}$ (MAT I + MAT II). Moreover, DMSO stimulation of MAT III allowed detection of a $17 \%$ decrease in the activity of the dimer (Table 2). These results suggested an increase in the activity of MAT I and II at the expense of MAT III. However, through this type of measurements we cannot correlate the changes in activity with those in protein or mRNA levels, and thus we cannot distinguish whether the alterations are due solely to the alterations of the levels of each isoenzyme or if there is also an effect of copper on catalysis.

It is well known that MAT $\alpha 1$ subunits associate into dimers (MAT III) and tetramers (MAT I), and that the ratio between these forms is displaced towards the dimer in liver diseases. Moreover, in many of these pathologies oxidative stress is 
produced, a mechanism known to inhibit MAT I/III. Thus, the net changes in MAT activity can be due to several factors: i) alterations in expression of this type of catalytic subunit; ii) its preferred association into one or another oligomeric assembly; iii) inhibition through mechanisms such as oxidation; or iv) a combination of these factors. Since a decrease in expression was already proved and activity data suggested a reduction in MAT III content, we next studied the possibility of changes in the oligomeric state due to copper accumulation by gel filtration chromatography (Figure 4). Activity profiles showed peaks corresponding to tetramers ( $\sim 200 \mathrm{kDa}$, MAT I and II) and dimers ( 110 kDa, MAT III) with higher activity levels for LE than for LEC rats. In addition, an increase in the activity of the tetramers could be observed in samples of the LEC group, although distinction between the contributions of MAT I and II was precluded due to coelution. In order to overcome this problem, we analyzed the fractions for the presence of MAT $\alpha 1$ protein using the specific antibody (Figure 4). Dot blots revealed a consistent increase in MAT I content and a reduction in that of MAT III in livers of LEC rats. Dimer/tetramer ratios estimated by activity measurements were calculated to be $5.48 \pm 1.31$ and $4.13 \pm 0.9(\mathrm{p}=0.263)$, and when calculated by protein levels values of $4.8 \pm 2.92$ and $3.87 \pm 1.3(\mathrm{p}=0.247)$ were found for LE and LEC groups, respectively. These values are not significant probably due to the low precision of this method, but represent the tendency observed in all the animals in each group. Elution patterns for BHMT, a tetramer, were not modified between animal groups (data not shown), and serve as an internal control of sample manipulation. Thus, this type of analysis suggests that copper accumulation has an effect on MAT $\alpha 1$ oligomerization.

Metals such as copper could exert their effects by direct binding to their target proteins or through their oxidation. As mentioned above MAT I/III is known to be highly susceptible to thiol oxidation, and such process leads to enzyme inactivation. 
Since an alteration of the GSH/GSSG ratio in LEC rats was detected, the possibility of MAT I/III thiol oxidation was also explored using bidimensional gels under nonreducing/reducing conditions. The results revealed no changes in the mobility pattern for this protein between animal groups (data not shown), thus suggesting no redox modification detectable by this technique. A parallel analysis carried out for BHMT showed also no change in the oxidation state of this enzyme.

As the mixture of MAT isoenzymes present in liver samples precluded analysis of copper effects on individual forms, but suggested alterations in subunit oligomerization and activity, we performed several in vitro assays using recombinant MAT catalytic subunits. First, the possibility of a copper effect on folding was explored by performing refolding assays of MAT $\alpha 1$ and MAT $\alpha 2$ subunits in the presence or absence of copper sulfate using protocols previously developed in our laboratory. In both cases, the recovery of active protein was reduced when this cation was present, but no influence in the association state (tetramers and dimers) attained was observed (data not shown). Moreover, the specific activity of the DTT-Cu-refolded MAT I/III was slightly higher than that of the DTT-refolded protein $(102.86 \pm 14.16$ vs. $91.81 \pm 5.37$ $\mathrm{nmol} / \mathrm{min} / \mathrm{mg} ; \mathrm{p}=0.047$ ), whereas a minimal difference was observed for MAT $\alpha 2$ $(53.87 \pm 0.59$ vs. $52.19 \pm 0.3 \mathrm{nmol} / \mathrm{min} / \mathrm{mg}, \mathrm{p}=0.012)$. Together these results suggest that copper could also affect the production of correctly folded protein.

Second, copper could also exert an effect on MAT activity. Thus, to analyze this point, the activity of the refolded MAT $\alpha$ subunits was assayed in the presence of copper sulfate. Since copper in vivo appears bound to different types of carriers our assays were performed in the presence of Tris or Tris/Glycine. The effects observed were independent of the metal carrier of choice, but were influenced by the redox conditions in the assay (Figure 5). MAT 22 was inhibited by copper in the presence of DTT with a 
calculated $\mathrm{IC}_{50}$ of $748.2 \pm 1.03 \mu \mathrm{M}$, whereas this $\mathrm{IC}_{50}$ value became $286.9 \pm 1.24 \mu \mathrm{M}$ in the absence of the reducing agent, thus decreasing 2.5-fold. On the other hand, the effects on MAT1 $\alpha$ activity dramatically depended on the redox conditions in which the protein was present. A slight activation was observed with DTT, whereas in its absence inhibition was detected $\left(\mathrm{IC}_{50} 39.04 \pm 1.09 \mu \mathrm{M}\right)$. These data indicated a higher susceptibility of MAT 22 activity to copper action under reducing conditions, whereas under low reducing conditions MAT $\alpha 1$ was inactivated at lower metal concentrations than MAT 2 2. In addition, copper inhibition of both types of catalytic subunits correlated with the appearance of high-Mr complexes, suggesting changes at the structural level. All these in vitro data together confirm the possibility of copper acting on the catalytic activity of MAT isoenzymes, their susceptibility depending on the redox environment.

The remaining question concerns the elucidation of the mechanisms underlying the striking reduction in MAT2B mRNA levels. In order to clarify this point hepatoma H35 cells were treated with copper sulfate alone or in combination with an antioxidant (NAC), a copper chelator (neocuproine) or an inducer of oxidative stress (BSO) and MAT2B mRNA levels evaluated by real-time RT-PCR (Figure 6). The results confirm the strong reduction in MAT2B expression induced by copper $(60 \%)$ and show increased expression under oxidative stress (40\%). Copper effects could only be prevented by BSO, whereas NAC and neocuproine were ineffective, the combined treatment with neocuproine and copper inducing a large percentage of cell death. Thus, these data indicate a redox mechanism as responsible for MAT2B repression by the metal. 


\section{DISCUSSION}

Alterations in liver methionine metabolism under pathological conditions have been known for more than 50 years $[31,32]$. The effects described include changes in expression, protein levels, enzyme activity and in some cases in the ratio of oligomeric isoforms [11-13,15,33]. A common fact for most of these pathologies is the development of oxidative stress, a condition known to regulate the activity of enzymes of the methionine cycle $[34,35]$. Efforts have been concentrated in the elucidation of the relationship between changes in this pathway and the development of cirrhosis and cancer [16,36,37], but scarce studies have been carried out for other disorders, such as Wilson's disease. In fact, only one report describing a reduction in MAT activity and AdoMet levels at the late stages of the disease in LEC rats has been published [19]. Thus, the possibility of early changes in this pathway has not been explored, and hence, its potential alteration as an initial event in Wilson's disease development ignored.

In the present work, we show that LEC rats in the early phase of copper accumulation already showed the typical reduction in liver size, as well as the copper and iron deposits previously described [8,38]. Changes in mRNA levels for enzymes of the methionine cycle were also detectable by real-time RT-PCR, these alterations being moderate for most of the proteins (Figure 7A). In fact, previous expression studies with ATP7B knockout mice (6 week old) reported weak effects on global amino acid metabolism [39]. In contrast, a large decrease in MAT2B expression in the LEC group was detected, although previous studies reported no MAT2B in normal rat livers and its increased expression in human cirrhosis and hepatoma [40]. Reductions in MAT1A mRNA levels in LEC rats appear compensated by increases in those of MAT2A, a common feature in hepatoma development [36]. Copper toxicity is known to produce a stress response that alters transcription of multiple genes involved in metal homeostasis 
and protection against metal-induced damage [41]. This effect takes place primarily through interaction of metal transcription factor-1 (MTF-1) with metal response elements (MREs) located at the promoters of the target genes, but also through antioxidant response elements (AREs), as has been reported for metallothionein [41]. Although consensus sequences for both types of regulatory elements have been published [41 and references therein], no such elements are known to exist in the promoters of eukaryotic methionine metabolism related genes. In fact, a close inspection of MAT2B promoter sequence did not show exact matches for any of them. However, our data with H35 cells indicate a redox mechanism as responsible for the copper effects on MAT2B. Such a regulatory mechanism could involve an indirect effect through the modulation of redox-controlled transcription factors, for some of which the MAT2B promoter contains consensus-binding sites (i.e. NFкB) [42]. In fact, the prevention of copper effects exerted by BSO in this cell model together with the lack of such a protective effects for combinations including NAC, suggests the need for $\mathrm{Cu}$ (II) reduction to $\mathrm{Cu}(\mathrm{I})$ to obtain the expression decrease. This reaction could lead to the production of hydroxyl radicals that may react with target transcription factors, which in its oxidized form act on the MAT2B promoter. Moreover, the induced cell death observed in treatments combining copper and neocuproine, a preferred $\mathrm{Cu}(\mathrm{I})$ chelator, indicate reduction of copper (II) allowing production of neocuproine- $\mathrm{Cu}(\mathrm{I})$ complexes that are known to be toxic [43].

The changes observed in mRNA correlate with those in protein levels for those enzymes for which antibodies are available. Metal stress regulation of MAT protein levels has been previously demonstrated in other organisms [44-46], thus suggesting it as a general regulatory mechanism for this family of highly homologous enzymes [47]. Effects in total MAT activity correlated with those in MAT1A transcripts and MAT $\alpha 1$ 
subunits, rather than with a combination of the expression changes observed for MAT $\alpha 1$ and MAT $\alpha 2$. Such a result reflects the differences in specific activity and affinities shown by the three mammalian isoenzymes [1] (Figure 7B). Thus, reductions in MAT $\alpha 1$ expression will decrease the amount of the isoenzymes with higher specific activity, which are the most abundant in normal liver [1], leading to a decrease in total activity. Indeed, MAT III decrease was confirmed by comparison of measurements made in the presence of DMSO and by gel filtration chromatography. The moderate increase in MAT II could not compensate for the decrease in MAT I/III function due to its lower specific activity. In contrast, at $60 \mu \mathrm{M}$ methionine a slight increase in MAT activity (MAT I and II) could be measured, MAT II being under saturating conditions. Diminished expression of the regulatory subunit (MAT2 $\beta$ ) reduced MAT II affinity for methionine to values close to those for MAT I and precluding their distinction [48]. These effects are also confirmed by measurement of the metabolite levels. Thus, the net decrease in MAT global activity correlates with the tendency of AdoMet levels to diminish in the LEC group (Figure 7A). On the other hand, the larger decrease in AdoHcy contrasts with the reduction in SAHH levels, indicating a higher rate of Hcy and adenosine production. Moreover, the lack of changes in Hcy levels detected indicates its consumption through trans-sulfuration and remethylation reactions, the increase in methionine concentration together with decreases in GSH levels indicating a preference for remethylation. Such an effect could be the result from the reduction in methionine consumption through AdoMet synthesis together with the modulation of inhibitory and stimulatory effects of this compound on BHMT and cystathione $\beta$ synthase activities, respectively [1]. The small changes in MS expression could then be compensated by an increased Hcy remethylation through BHMT that guaranties recovery of methionine to sustain the AdoMet needs. 
Effects on activity could also rely either in copper catalyzed hydroxyl radical production and the corresponding alterations in the GSH/GSSG ratio or in binding to protein sulfhydryl groups [6]. Both processes could reduce MAT I/III catalysis through oxidation [37,49], including modification of cysteine 121 at the loop of access to the active site [49]. In the present study we have demonstrated inhibition by copper using the refolded MAT catalytic subunits, and the highest susceptibility of MAT $\alpha 1$ subunits (those with $\mathrm{C} 121$ ) under low reducing conditions. In fact, the calculated $\mathrm{IC}_{50}$ values suggest the relevance of these effects for MAT $\alpha 1$ in vivo, as was previously suggested for copper inhibition of SAHH [18], another of the enzymes showing decreased expression in LEC rats. Measurements of glutathione levels at these early phases of disease demonstrate that GSH concentrations are being reduced ( $30 \%)$, whereas GSSG levels tend to increase, and hence, a moderate oxidative stress is being reached in the tissue [50]. These conditions are known to modulate MAT I/III as it has been demonstrated in vivo [36] and in vitro [37].

The decreased expression of MAT $\alpha 1$ in LEC rats correlated with accumulation of tetramers (MAT I), in contrast with data obtained from cirrhotic samples and in galactosamine-treated animals [15]. Only certain degree of cross-reactivity with MAT $\alpha 2$ could explain such behavior, since several factors, and among them oxidative stress, are known to favor MAT III accumulation [28,37]. Our data excluded disulfide production in MAT $\alpha 1$, and could not relate the increased specific activity due DTTcopper refolding to changes in dimer to tetramer association, but conformational alterations due to copper cannot be excluded as shown by the in vitro results presented. The need for chaperone assisted folding deduced from E. coli MAT binding to GroEL/GroES suggests that in vivo copper effects on folding of MAT catalytic subunits may occur through metallochaperones, a possibility that deserves additional studies. 
In summary, our results demonstrate an early alteration of methionine metabolism in LEC rats that might contribute to disease development. This effect is exerted through redox-mediated mechanisms at several levels that include protein expression and activity. Moreover, at these initial steps of disease the expected MAT $\alpha 1$ to MAT 22 expression switch is already observed, but, in contrast, MAT2B expression drastically diminishes providing an additional effect on MAT activity due to a reduction of MAT II hetero-oligomers and the corresponding decrease in methionine affinity. Further effects of copper accumulation could also be expected on MAT folding as suggested by in vitro experiments, actions that could be exerted through redox-mediated mechanisms involving thiol-transferases and metallochaperones. 


\section{ACKNOWLEDGEMENTS}

This work was supported by grants of the Ministerio de Educación y Ciencia (BMC2002-00243 and BFU2005-00050 to M.A.P. and SAF2006-03489 to D.P-S.) and the Fondo de Investigación Sanitaria del Instituto de Salud Carlos III (RCMN C03/08 to M.A.P.). M. D. was supported by fellowships of the RCMN C03/08 and PI05/0563 grants of the Fondo de Investigación Sanitaria del Instituto de Salud Carlos III. The authors wish to thank Dr. D. Kloor for providing the anti-SAHH antibody, Eva Fernández, M. Jesús Carrasco and Nieves Serranos for technical assistance.

\section{ABBREVIATIONS}

AdoMet, S-adenosylmethionine; AdoHcy, S-adenosylhomocysteine; Hcy, homocysteine; GSH, reduced glutathione; GSSG, oxidized glutathione; MAT, methionine adenosyltransferase; BHMT, betaine homocysteine S-methyltransferase; MS, methionine synthase; SAHH, S-adenosylmethionine hydrolase; CBS, cystathionine $\beta$ synthase; NAC, N-acetylcysteine; BSO, buthionine sulfoximine.

Supplementary material can be obtained at http://www2.iib.uam.es/mapajares_lab/cmls2008/ 


\section{REFERENCES}

1. Mato, J. M., Alvarez, L., Ortiz, P. and Pajares, M.A. (1997) Sadenosylmethionine synthesis: molecular mechanisms and clinical implications. Pharmacol. Ther. 73, 265-280.

2. Sternlieb, I. (1994) Copper and Zinc. In: The Liver: Biology and Pathobiology 3rd ed. , pp. 585-596, Arias, I. M., Boyer, J. L., Fausto, W., Jakoby, W. B., Schachter, D. and Shafritz, D.A. (eds.) Raven Press, New York.

3. Balamurugan, K. and Schaffner, W. (2006) Copper homeostasis in eukaryotes: teetering on a tightrope. Biochim. Biophys. Acta 1763, 737-746.

4. Madsen, E. and Gitlin, J.D. (2007) Copper deficiency. Curr. Opin. Gastroenterol. 23, 187-192.

5. Nose, Y., Rees, E. M. and Thiele, D. J. (2006) Structure of the Ctr1 copper trans'PORE'ter reveals novel architecture. Trends Biochem. Sci. 31, 604-607.

6. Theophanides, T. and Anastassopoulou, J. (2002) Copper and carcinogenesis. Crit. Rev. Oncol. Hematol. 42, 57-64.

7. Ala, A., Walker, A.P., Ashkan, K., Dooley, J. S. and Schilsky, M. L. (2007) Wilson's disease. Lancet 369, 397-408.

8. Fuentealba, I.C. and Aburto, E.M. (2003) Animal models of copper-associated liver disease. Comp. Hepatol. 2, 5-.

9. Sone, K., Maeda, M., Wakabayashi. K., Takeichi, N., Mori, M., Sugimura, T. and Nagao, M. (1996) Inhibition of hereditary hepatitis and liver tumor development in Long-Evans cinnamon rats by the copper-chelating agent trientine dihydrochloride. Hepatology 23, 764-770. 
10. Wu, J., Forbes, J. R., Chen, H. S. and Cox, D.W. (1994) The LEC rat has a deletion in the copper transporting ATPase gene homologous to the Wilson disease gene. Nat. Genet. 7, 541-545.

11. Pajares, M. A. and Perez-Sala, D. (2006) Betaine homocysteine Smethyltransferase: just a regulator of homocysteine metabolism? Cell. Mol. Life Sci. 63, 2792-2803.

12. Avila, M. A., Berasain, C., Torres, L., Martín-Duce, A., Corrales, F. J., Yang, H., Prieto, J., Lu, S. C., Caballería, J., Rodés, J. and Mato, J. M. (2000) Reduced mRNA abundance of the main enzymes involved in methionine metabolism in human liver cirrhosis and hepatocellular carcinoma. J. Hepatol. 33, 907-914.

13. Forestier, M., Banninger, R., Reichen, J. and Solloz, M. (2003) Betaine homocysteine methyltransferase: gene cloning and expression analysis in rat liver cirrhosis. Biochim. Biophys. Acta 1638, 29-34.

14. Yang, H., Sadda, M. R., Yu, V., Zeng, Y., Lee, T. D. and Ou, X. (2003) Induction of human methionine adenosyltransferase $2 \mathrm{~A}$ expression by tumor necrosis factor alpha. Role of NF-kappa B and AP-1. J. Biol. Chem. 278, 5088750896.

15. Cabrero, C., Martín-Duce, A., Ortiz, P., Alemany, S. and Mato, J. M. (1988) Specific loss of the high-molecular-weight form of S-adenosyl-L-methionine synthetase in human liver cirrhosis. Hepatology 8, 1530-1534.

16. Lu, S. C., Alvarez, L., Huang, Z. Z., Chen, L., An, W., Corrales, F. J., Avila, M. A., Kanel, G. and Mato, J. M. (2001) Methionine adenosyltransferase 1A knockout mice are predisposed to liver injury and exhibit increased expression of genes involved in proliferation. Proc. Natl. Acad. Sci. U S A 98, 5560-5565.

17. Mato, J. M. and Lu, S. C. (2007) Role of S-adenosyl-L-methionine in liver health 
and injury. Hepatology 45, 1306-1312.

18. Li, Y., Chen, J., Liu, J., Yang, X. and Wang, K. (2004) Binding of Cu2+ to Sadenosyl-L-homocysteine hydrolase. J. Inorg. Biochem. 98, 977-983.

19. Shimizu, K., Abe, M., Yokoyama, S., Takahashi, H., Sawada, N. and Mori, M. (1990) Decreased activities of S-adenosylmethionine synthetase isozymes in hereditary hepatitis in Long-Evans rats. Life Sci. 46, 1837-1842.

20. Jain, S., Scheuer, P. J., Archer, B., Newman, S. P. and Sherlock, S. (1978) Histological demonstration of copper and copper-associated protein in chronic liver diseases. J. Clin. Pathol. 31, 784-790.

21. Klavins, J. V., Pickett, J. P. and Wessely, Z. (1976) Staining of minerals and solubility of iron in tissues. Ann. Clin. Lab. Sci. 6, 214-222.

22. Pfaffl, M. W. (2001) A new mathematical model for relative quantification in real-time RT-PCR. Nucleic Acids Res. 29, e45.

23. Gil, B., Pajares, M. A., Mato, J. M. and Alvarez, L. (1997) Glucocorticoid regulation of hepatic S-adenosylmethionine synthetase gene expression. Endocrinology 138, 1251-1258.

24. Finkelstein, J. D. and Mudd, S. H. (1967) Trans-sulfuration in mammals. The methionine-sparing effect of cystine. J. Biol. Chem. 242, 873-880.

25. Mingorance, J., Alvarez, L., Sánchez-Góngora, E., Mato, J. M. and Pajares, M. A. (1996) Site-directed mutagenesis of rat liver S-adenosylmethionine synthetase. Identification of a cysteine residue critical for the oligomeric state. Biochem. J. 315, 761-776.

26. Gonzalez, B., Campillo, N., Garrido, F., Gasset, M., Sanz-Aparicio, J. and Pajares, M. A. (2003) Active-site-mutagenesis study of rat liver betainehomocysteine S-methyltransferase. Biochem. J. 370, 945-952. 
27. Kloor, D., Kurz, J., Fuchs, S., Faust, B. and Osswald, H. (1996) Sadenosylhomocysteine-hydrolase from bovine kidney: enzymatic and binding properties. Kidney Blood Press. Res. 19, 100-108.

28. Sanchez-Perez, G. F., Gasset, M., Calvete, J. J. and Pajares, M. A. (2003) Role of an intrasubunit disulfide in the association state of the cytosolic homooligomer methionine adenosyltransferase. J. Biol. Chem. 278, 7285-7293.

29. Cumming, R. C., Andon, N. L., Haynes, P. A., Park, M., Fischer, W. H. and Schubert, D. (2004) Protein disulfide bond formation in the cytoplasm during oxidative stress. J. Biol. Chem. 279, 21749-21758.

30. Lopez-Vara, M. C., Gasset, M. and Pajares, M. A. (2000) Refolding and characterization of rat liver methionine adenosyltransferase from Escherichia coli inclusion bodies. Protein Expr. Purif. 19, 219-226.

31. Kinsell, L. W., Harper, H. A., Barton, H. C., Michaels, G. D. and Weiss, H. A. (1947) Rate of Disappearance From Plasma of Intravenously Administered Methionine in Patients With Liver Damage. Science 106, 589-590.

32. Horowitz, J. H., Rypins, E. B., Henderson, J. M., Heymsfield, S. B., Moffitt, S. D., Bain, R. P., Chawla, R. K., Bleier, J.C. and Rudman, D. (1981) Evidence for impairment of transsulfuration pathway in cirrhosis. Gastroenterology 81, 668675.

33. Liang, C. R., Leow, C. K., Neo, J. C., Tan, G. S., Lo, S. L., Lim, J. W., Seow, T. K., Lai, P. B. and Chung, M. C. (2005) Proteome analysis of human hepatocellular carcinoma tissues by two-dimensional difference gel electrophoresis and mass spectrometry. Proteomics 5, 2258-2271. 
34. Huang, Z. Z., Mato, J. M., Kanel, G. and Lu, S. C. (1999) Differential effect of thioacetamide on hepatic methionine adenosyltransferase expression in the rat. Hepatology 29, 1471-1478.

35. Mato, J. M., Cámara, J., Fernández de Paz, J., Caballería, L., Coll, S., Caballero, A., Garcia-Buey, L., Beltran, J., Benita, V., Caballeria, J., Sola, R., MorenoOtero, R., Barrao, F., Martin-Duce, A., Correa, J. A., Pares, A., Barrao, E., Garcia-Magaz, I., Puerta, J. L., Moreno, J., Boissard, G., Ortiz, P. and Rodes, J. (1999) S-adenosylmethionine in alcoholic liver cirrhosis: a randomized, placebocontrolled, double-blind, multicenter clinical trial. J. Hepatol. 30, 1081-1089.

36. Corrales, F., Ochoa, P., Rivas, C., Martín-Lomas, M., Mato, J. M. and Pajares, M. A. (1991) Inhibition of glutathione synthesis in the liver leads to S-adenosylL-methionine synthetase reduction. Hepatology 14, 528-533.

37. Pajares, M. A., Durán, C., Corrales, F., Pliego, M. M. and Mato, J. M. (1992) Modulation of rat liver S-adenosylmethionine synthetase activity by glutathione. J. Biol. Chem. 267, 17598-17605.

38. Sharp, P. (2004) The molecular basis of copper and iron interactions. Proc. Nutr. Soc. $63,563-569$.

39. Huster, D., Purnat, T. D., Burkhead, J. L., Ralle, M., Fiehn, O., Stuckert, F., Olson, N. E., Teupser, D. and Lutsenko, S. (2007) High copper selectively alters lipid metabolism and cell cycle machinery in the mouse model of Wilson disease. J. Biol. Chem. 282, 8343-8355.

40. Martinez-Chantar, M. L., García-Trevijano, E. R., Latasa, M. U., Martín-Duce, A., Fortes, P., Caballería, J., Avila, M. A. and Mato, J. M. (2003) Methionine adenosyltransferase II beta subunit gene expression provides a proliferative advantage in human hepatoma. Gastroenterology 124, 940-948. 
41. Mattie, M. D. and Freedman, J. H. (2004) Copper-inducible transcription: regulation by metal- and oxidative stress-responsive pathways. Am. J. Physiol. Cell. Physiol. 286, C293-301.

42. Yang, H., Ara, A. I., Magilnick, N.Xia, M., Ramani, K., Chen, H., Lee, T. D., Mato, J. M. and Lu, S. C. (2008) Expression pattern, regulation, and functions of methionine adenosyltransferase 2beta splicing variants in hepatoma cells. Gastroenterology 134, 281-291.

43. Chen, S-H., Lin, J-K., Liu, S-H., Liang, Y-C. and Lin-Shiau, S-Y. (2008) Apoptosis of cultured astrocytes induced by the copper and neocuproine complex through oxidative stress and JNK activation. Toxicol. Sci. 102, 138-149.

44. Yang, Q., Wang, Y., Zhang, J., Shi, W., Qian, C. and Peng, X. (2007) Identification of aluminum-responsive proteins in rice roots by a proteomic approach: cysteine synthase as a key player in Al response. Proteomics 7, 737749.

45. Ferianc, P., Farewell, A. and Nystrom, T. (1998) The cadmium-stress stimulon of Escherichia coli K-12. Microbiology 144, 1045-1050.

46. Mohamed Fahmy Gad El-Rab, S., Abdel-Fattah Shoreit, A. and Fukumori, Y. (2006) Effects of cadmium stress on growth, morphology, and protein expression in Rhodobacter capsulatus B10. Biosci. Biotechnol. Biochem. 70, 2394-2402.

47. Sanchez-Perez, G. F., Bautista, J. M. and Pajares, M. A. (2004) Methionine adenosyltransferase as a useful molecular systematics tool revealed by phylogenetic and structural analyses. J. Mol. Biol. 335, 693-706.

48. Halim, A. B., LeGros, L., Geller, A. and Kotb, M. (1999) Expression and functional interaction of the catalytic and regulatory subunits of human 
methionine adenosyltransferase in mammalian cells. J. Biol. Chem. 274, 297202975.

49. Sanchez-Gongora, E., Ruiz, F., Mingorance, J., An, W., Corrales, F. J. and Mato, J. M. (1997) Interaction of liver methionine adenosyltransferase with hydroxyl radical. FASEB J. 11, 1013-1019.

50. Martínez-Chantar, M. L. and Pajares, M. A. (1996) Role of thioltranferases on the modulation of rat liver S-adenosylmethionine synthetase activity by glutathione. FEBS Lett. 397, 293-297. 


\section{TABLES}

\section{Table 1}

Measurements of metabolite levels in liver. The levels of metabolites of the methionine cycle, as well as of GSH and GSSG were measured in liver samples of control and LEC rats using mass spectrometry analysis. The results are expressed as the mean $\pm \mathrm{SD}$ of the nmoles quantified per gram of tissue for each group.

\begin{tabular}{|l|c|c|}
\hline & $\begin{array}{c}\text { LE } \\
(\mathbf{n}=\mathbf{5})\end{array}$ & $\begin{array}{c}\text { LEC } \\
(\mathbf{n}=\mathbf{4})\end{array}$ \\
\hline AdoMet $(\mathbf{n m o l} / \mathbf{g}) *$ & $45.64 \pm 13.25$ & $35.15 \pm 9.90$ \\
\hline AdoHcy $(\mathbf{n m o l} / \mathbf{g})$ & $32.52 \pm 8.56$ & $20.08 \pm 5.41$ \\
\hline Hcy $(\mathbf{n m o l} / \mathbf{g}) *$ & $1.51 \pm 0.3 * *$ & $1.55 \pm 0.42^{* *}$ \\
\hline Methionine (nmol/g) & $121.9 \pm 7.35$ & $171.9 \pm 45.39$ \\
\hline GSH $(\mu \mathbf{m o l} / \mathbf{g})$ & $5.81 \pm 0.27$ & $3.96 \pm 1.15$ \\
\hline GSSG (nmol/g)* & $228.6 \pm 34.07$ & $270.05 \pm 106.6$ \\
\hline GSH/GSSG* & $25.90 \pm 4.36$ & $20.31 \pm 13.67$ \\
\hline
\end{tabular}

$* \mathrm{p}>0.05$, non significant

**values at the detection limit 


\section{Table 2}

Activity measurements. MAT and BHMT activities were measured in liver cytosol as described under Materials and Methods. The data shown are the mean \pm SD of measurements made in triplicate for every individual in each group.

\begin{tabular}{|c|c|c|c|c|}
\hline & & $\begin{array}{c}\text { LE } \\
(\mathbf{n = 5})\end{array}$ & $\begin{array}{c}\text { LEC } \\
(\mathbf{n = 6})\end{array}$ & p \\
\hline \multirow{3}{*}{$\begin{array}{c}\text { MAT } \\
(\mathbf{p m o l} / \mathbf{m i n} / \mathbf{m g})\end{array}$} & $\begin{array}{c}60 \mu \mathrm{MM} \text { Met } \\
\text { DMSO }\end{array}$ & $73.19 \pm 6.49$ & $85.73 \pm 9.32$ & 0.006 \\
\cline { 2 - 5 } & $5 \mathrm{mM} \mathrm{Met}$ & $476.94 \pm 162.23$ & $339.9 \pm 115.53$ & 0.013 \\
\hline $\begin{array}{c}\text { BHMT } \\
(\mathbf{n m o l} / \mathbf{m i n} / \mathbf{m g})\end{array}$ & & $0.533 \pm 0.07$ & $0.517 \pm 0.085$ & 0.334 \\
\hline
\end{tabular}




\section{FIGURE LEGENDS}

Figure 1. Histological evaluation of the LEC rat livers. Paraffin embedded sections of LE (A through C) and LEC livers (D through F) of 9 weeks old rats were prepared and histologically characterized. For this purpose, hematoxilin/eosin (A, D) or metal specific staining techniques were used. The figure shows representative panels proving the presence of copper $(\mathrm{B}, \mathrm{E})$ and iron deposits $(\mathrm{C}, \mathrm{F})$ stained as black and dark brown spots, respectively. The horizontal bar represents $10 \mu \mathrm{m}$.

Figure 2. Analysis of the mRNA changes by real-time RT-PCR. Changes in mRNA levels for the enzymes involved in the hepatic methionine cycle were analyzed by real-time RT-PCR using the primers included in table 1 and SybrGreen dye. Experimental efficiencies for each transcript were calculated and used to determine the fold change according to the method of Pfaffl [22]. The histogram shows the fold change calculated against the control group using $18 \mathrm{~S}$ rRNA as the reference. Statistical evaluation was performed using ratios for each individual vs $18 \mathrm{~S}$ rRNA. ${ }^{*} \mathrm{p}<0.05$ (LE group $n=5$, LEC group $n=6$ ).

Figure 3. Western blot analysis. Samples of cytosols $(25 \mu \mathrm{g})$ from LE and LEC rats were loaded on SDS-PAGE gels for immunoblotting using either anti-MAT I/III, anti-BHMT, anti-SAHH or anti- $\alpha$-tubulin antisera. The densitometric scans of the gels were corrected against the tubulin signal used as a control. The histogram presents the mean \pm SD of the corrected data of samples for each group (LE $n=5$ and $\operatorname{LEC~} n=6$ ). On the other hand, the insert shows blots of representative samples.

Figure 4. Gel filtration chromatography profiles of MAT elution. Cytosolic samples of LE and LEC rats (1 mg) were loaded on a Superose 12/10 HR column and fractions of the elution profile collected. Samples of these fractions were used to measure total MAT activity at $5 \mathrm{mM}$ methionine $(\bullet)$, and for dot-blot analysis of 
MAT $\alpha 1$ protein localization ( $\boldsymbol{\square})$. The figure shows profiles of representative samples. The elution position of the markers is shown in the figure and was as follows: blue dextran (2000 kDa, $7.66 \mathrm{ml})$, apoferritin (443 kDa, $9.87 \mathrm{ml}, \mathrm{a}), \beta$-amylase (200 kDa, $11.97 \mathrm{ml}, \mathrm{b})$, alcohol dehydrogenase $(150 \mathrm{kDa}, 12.81 \mathrm{ml}, \mathrm{c})$, carbonic anhydrase (29 $\mathrm{kDa}, 15.12 \mathrm{ml}, \mathrm{d})$ and ATP (551 Da, $19.26 \mathrm{ml})$.

Figure 5. Effect of copper on MAT activity in vitro. Recombinant MAT $\alpha 1$ and MAT $\alpha 2$ were obtained by refolding using the procedure of López-Vara et al. [30]. The effect of copper on their catalytic activities was then analyzed in the presence or absence $(O)$ of reducing agents at $5 \mathrm{mM}$ methionine. The figure shows results of a typical experiment carried out for MAT $\alpha 1$ (panel A) and MAT $\alpha 2$ (panel B). The results for each point are expressed as the mean \pm SD of the triplicates obtained.

Figure 6. Changes of MAT2B expression in H35 cells. Hepatoma H35 cells were treated with copper $(1 \mathrm{mM})$, NAC $(5 \mathrm{mM})$, neocuproine $(10 \mu \mathrm{M})$, BSO $(1 \mathrm{mM})$ or the combination of these agents with the metal. NAC and BSO treatments were initiated 8 hours before addition of the metal, whereas for neocuproine this period was 2 hours. In all the cases copper treatments lasted 24 hours before RNA isolation. The effects on MAT2B expression levels were then evaluated by real-time PCR. The figure shows the results (mean $\pm \mathrm{SD}$ ) of a typical experiment carried out in triplicate.

Figure 7. Copper regulation of the methionine cycle in early phases of Wilson's disease. The figure summarizes the effects of copper on metabolite and enzyme levels as measured in this work in vivo. Arrows indicate the sign of the changes observed (red) and deduced (blue), and their thickness the extent of the variation. Panel A shows the changes in expression detected, as well as those in the metabolite levels of the cycle and in GSH and GSSG. The inhibitory and stimulatory effects of the copperinduced alterations in the GSH/GSSG ratio and AdoMet levels on the activities of 
several enzymes are also depicted. At these early phases of disease a reduction in expression for most of the enzymes of the cycle is observed that initiates a decrease in the flow through this pathway as shown by diminution in the metabolite levels and the slight increase in methionine. Additional actions on folding through metallochaperones and activities through redox modulation (on MAT I/III) and changes in AdoMet levels (on BHMT and CBS) can also be expected. Panel B shows in vivo results concerning MAT isoenzymes. Cooper induced reductions or increases in mRNA expression are indicated circled according to its sign. The large decrease in MAT 2B mRNA (80\%) is expected to result in a reduction in the amount of regulatory subunit, and hence to a diminishment in that of the MAT II hetero-oligomers. In parallel, the decrease in MAT $\alpha 1$ production is compensated by a similar increase in MAT $\alpha 2$ subunits, both preferring tetramer association pattern under these conditions. However, these oligomeric assemblies are known to display intermediate affinities for methionine that together with their lower AdoMet synthesizing capacity and the modulation of MAT I/III though GSH/GSSG ratios renders reduced total activity. A reflect of these combined changes is the tendency of AdoMet levels to decrease in the LEC group. 

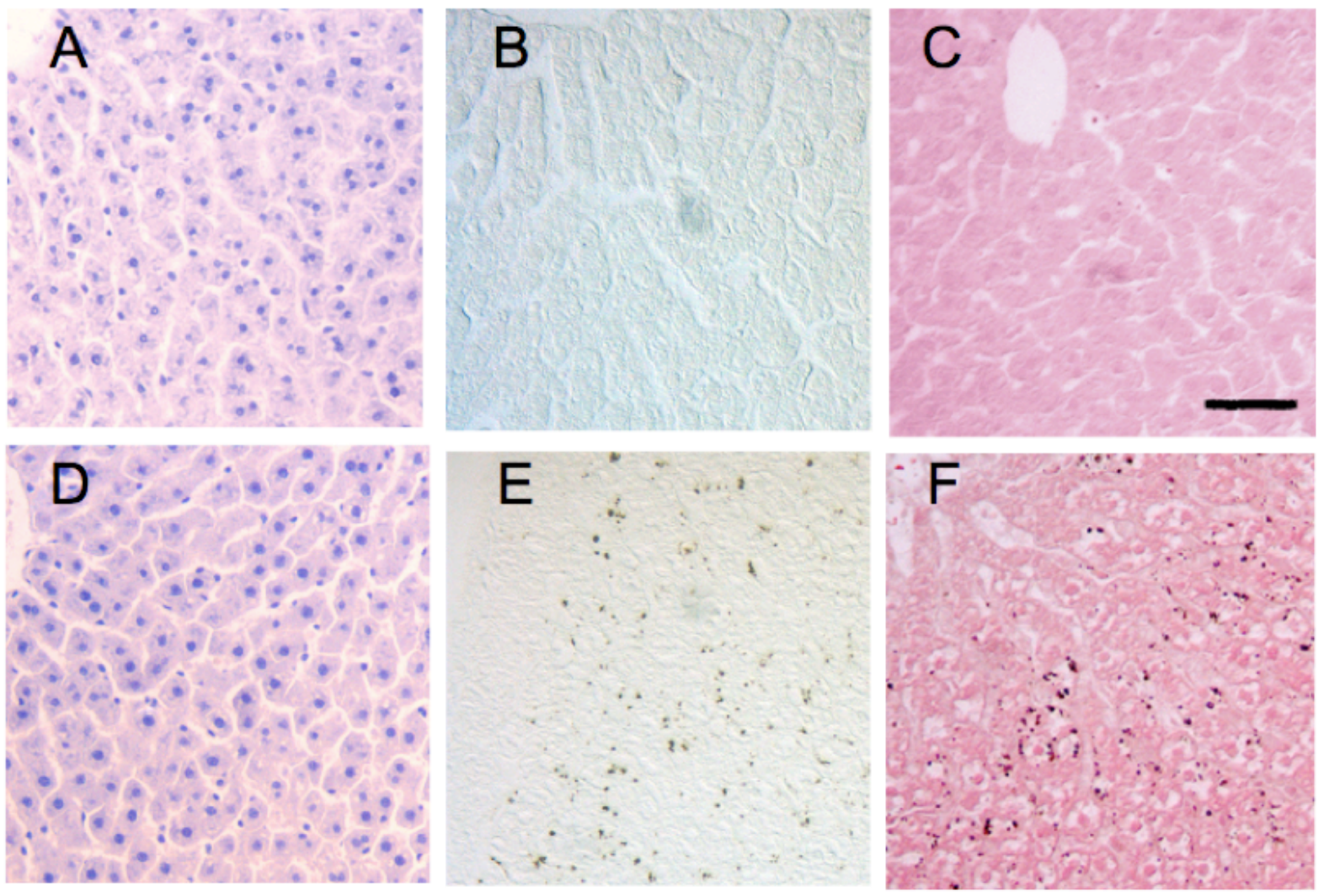


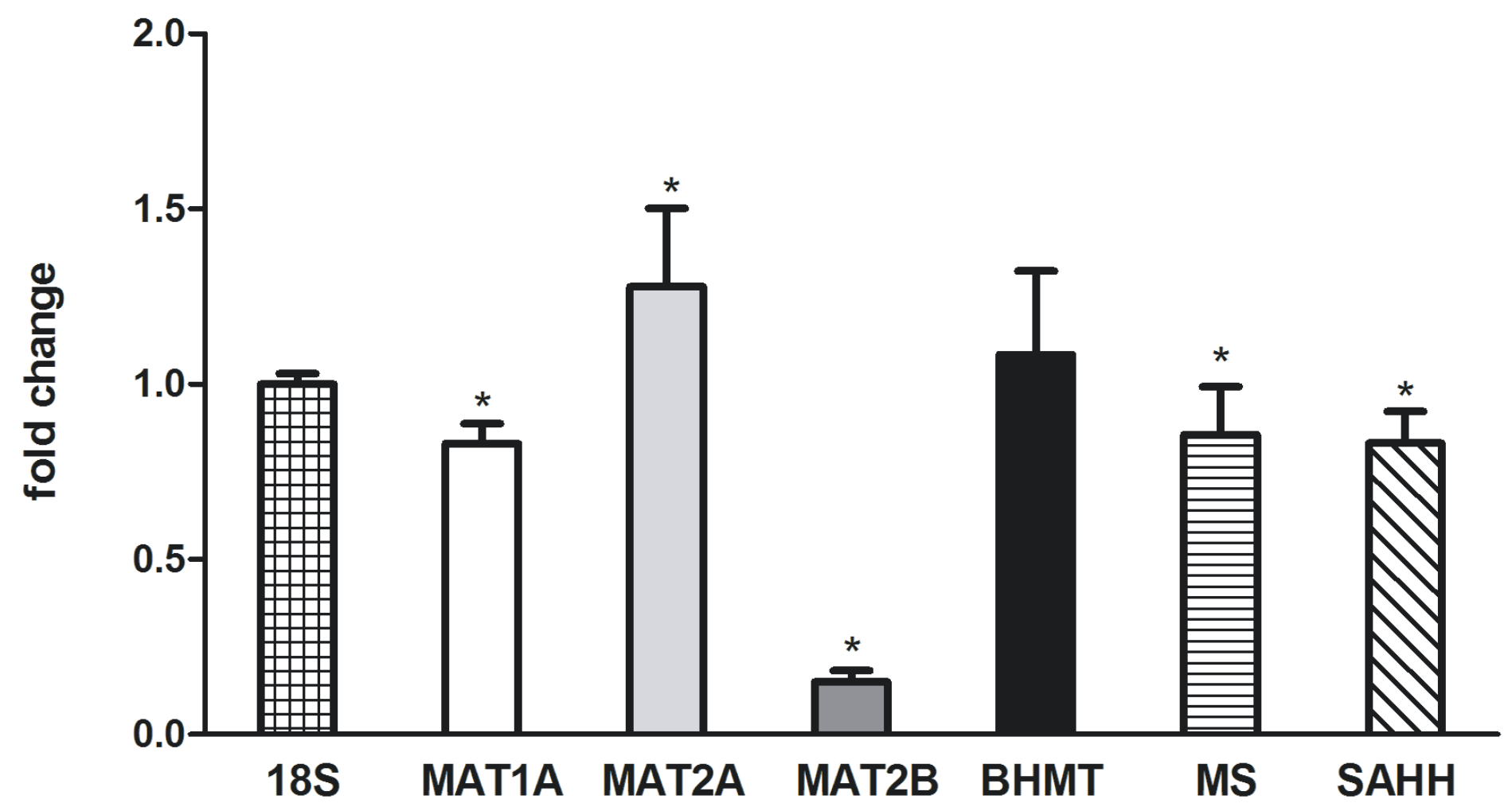




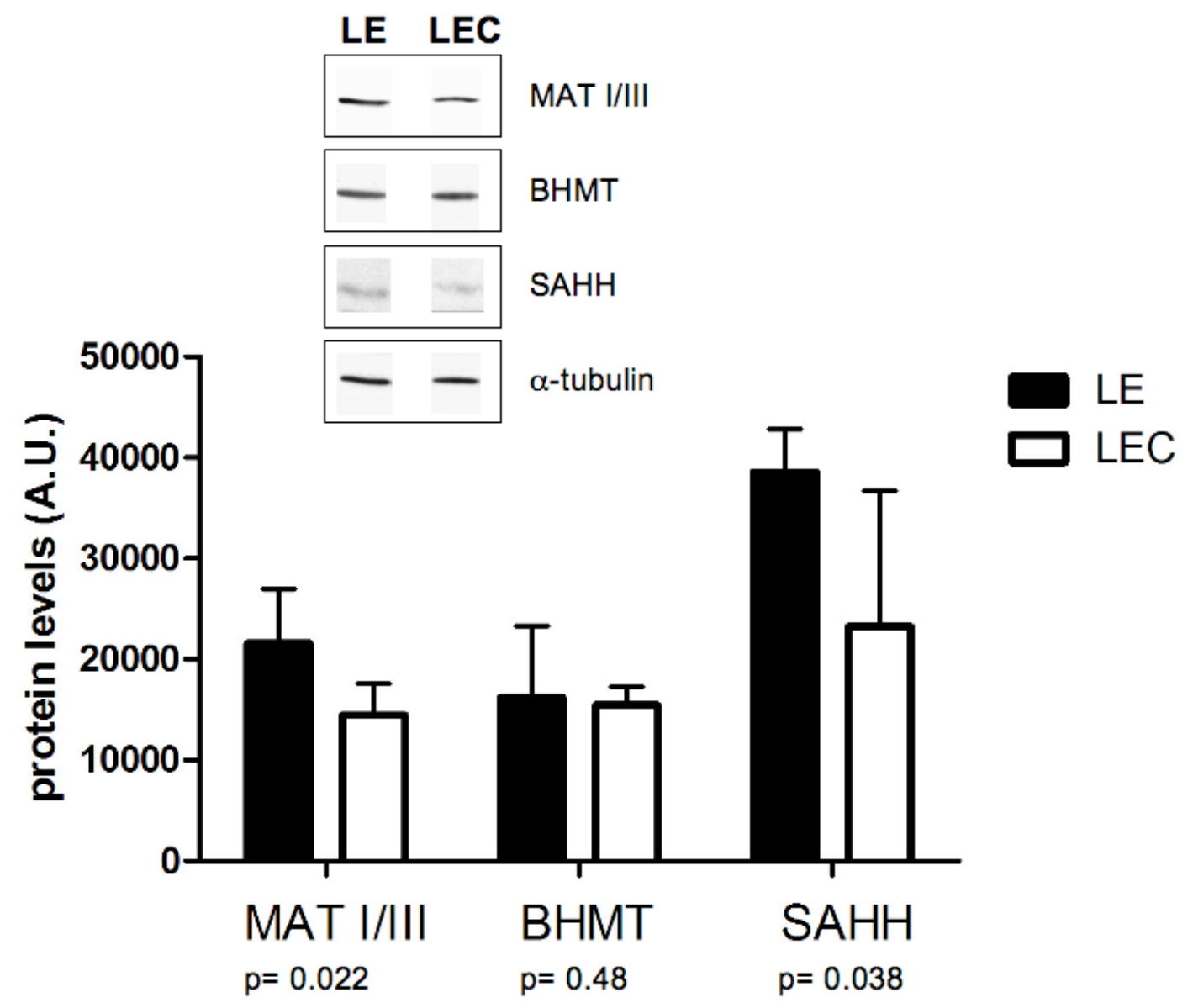



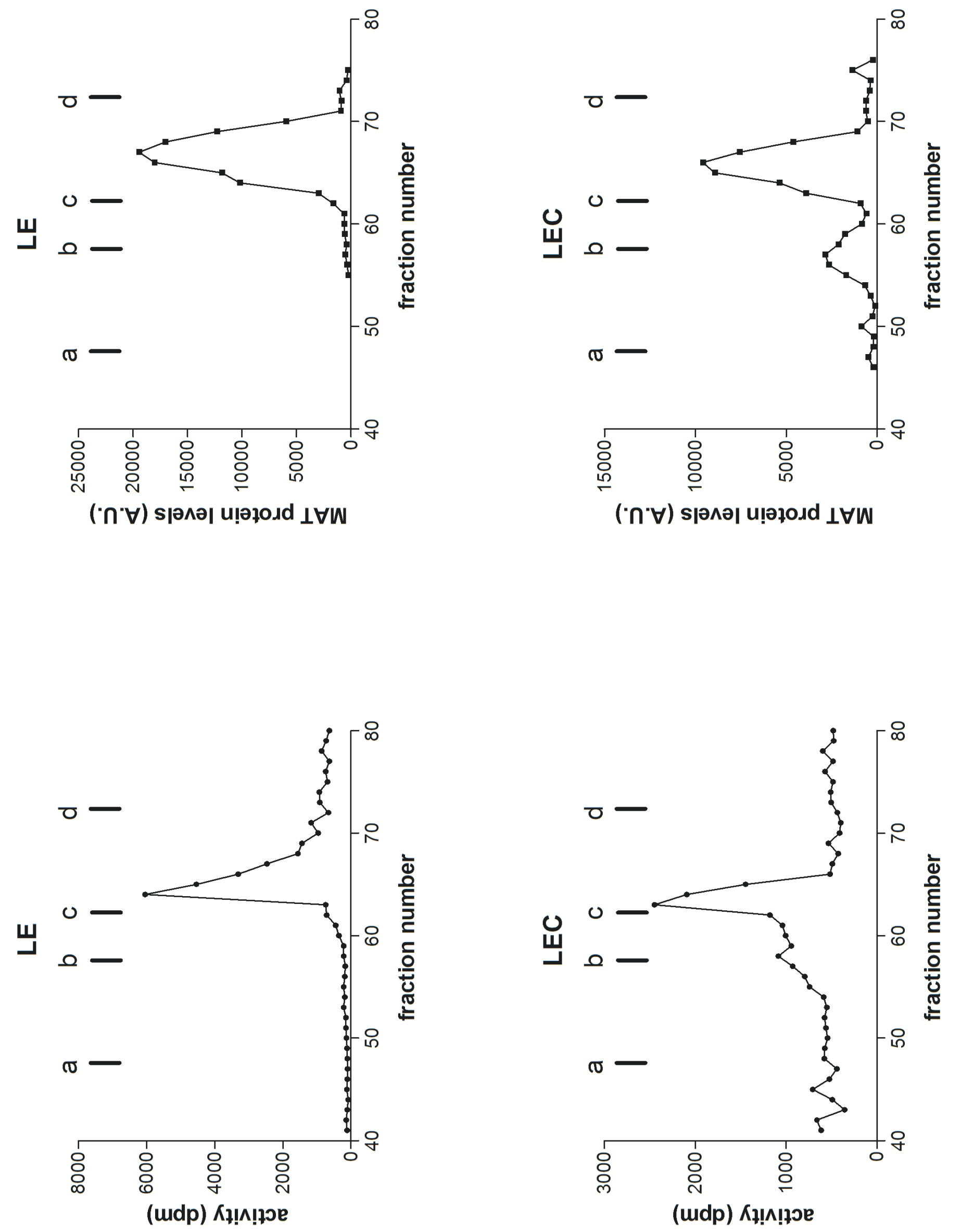
A
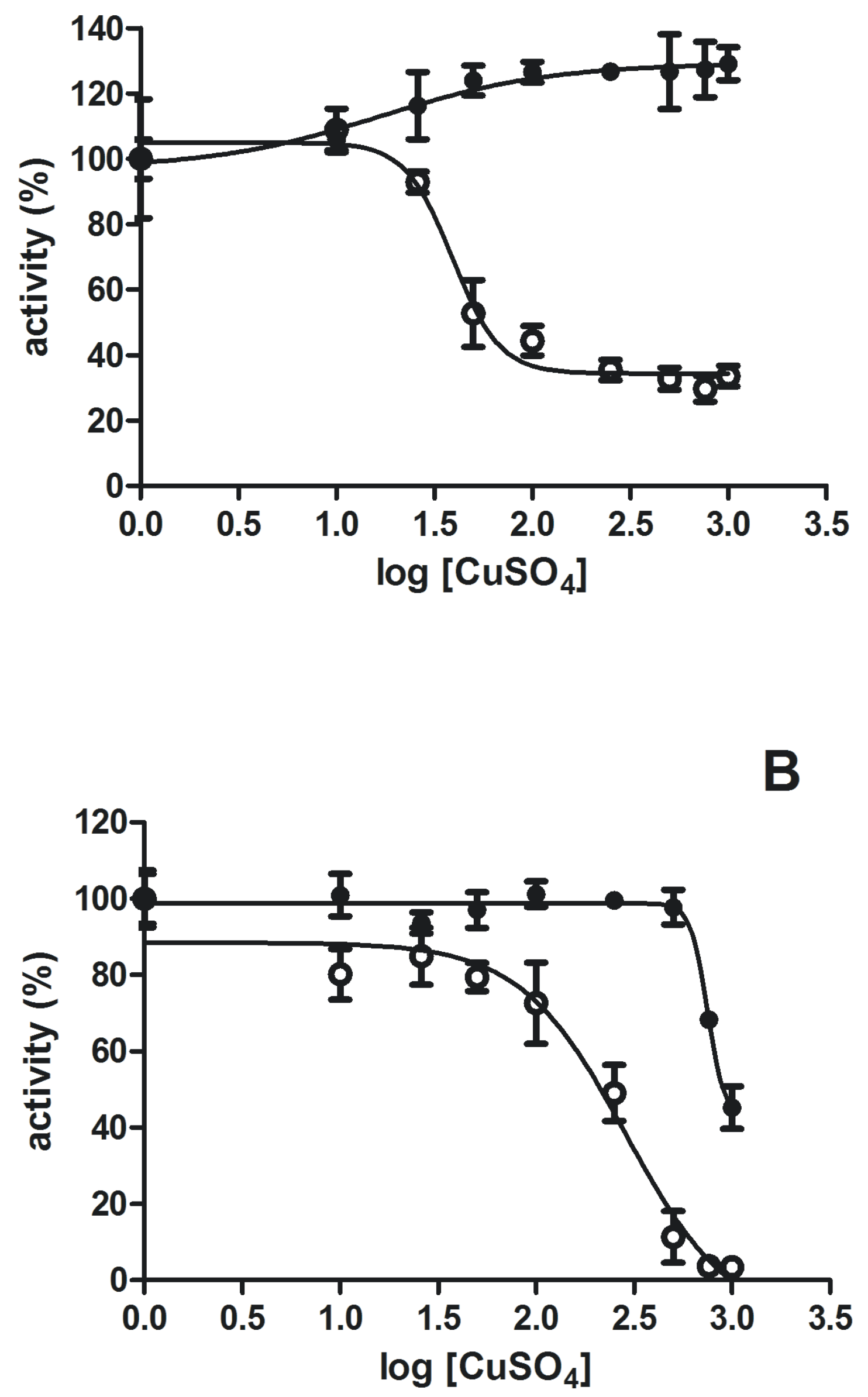


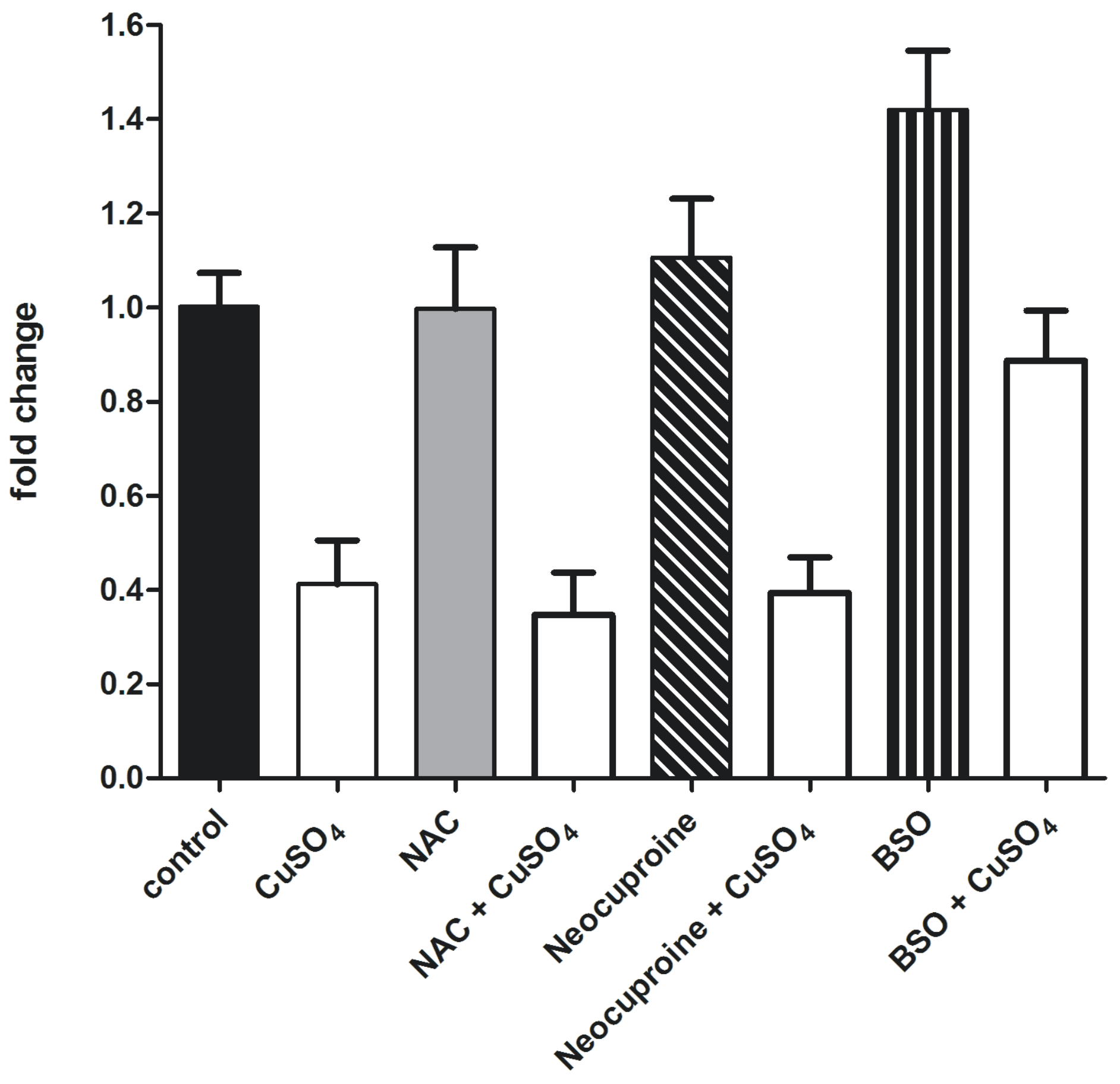




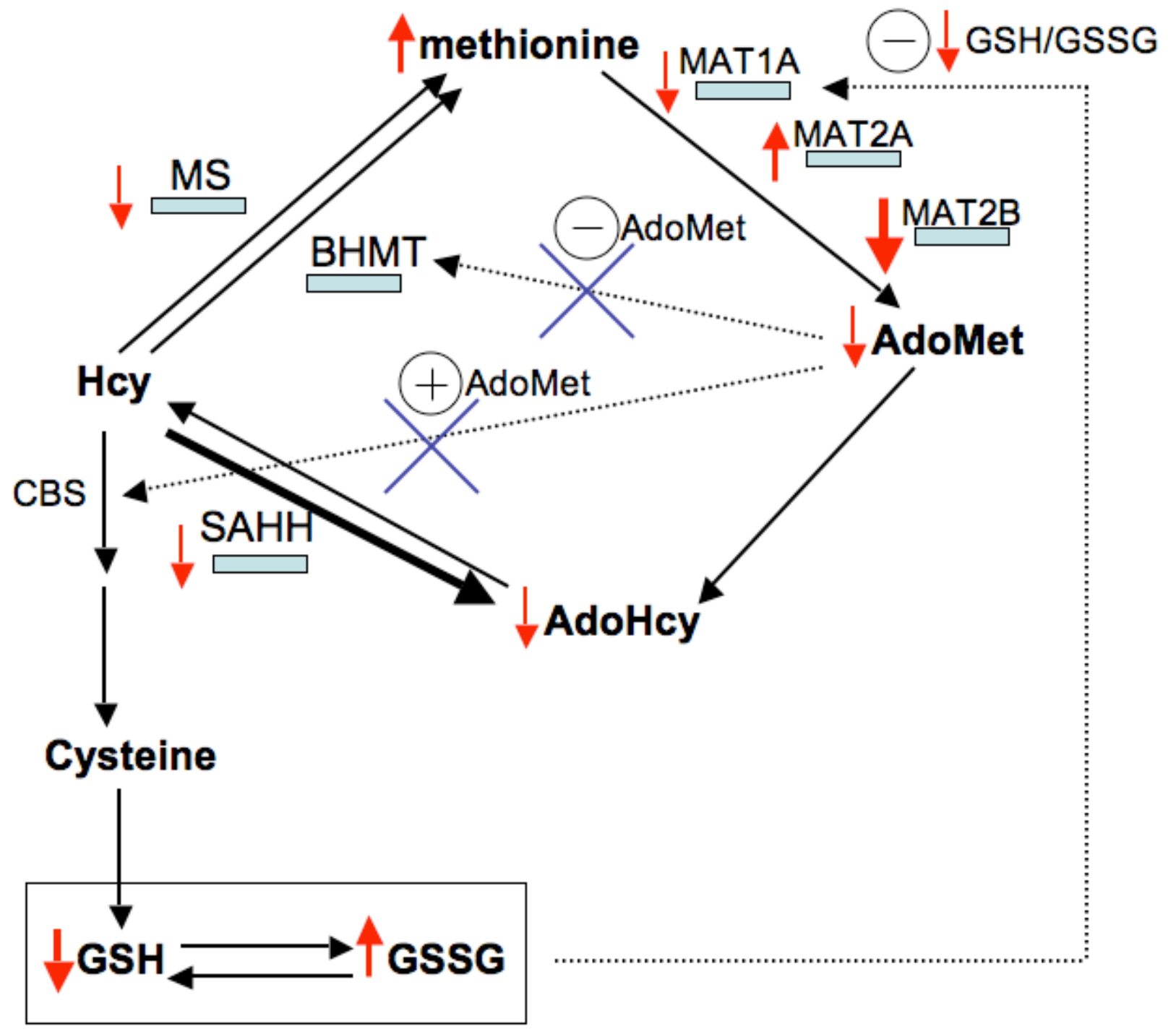




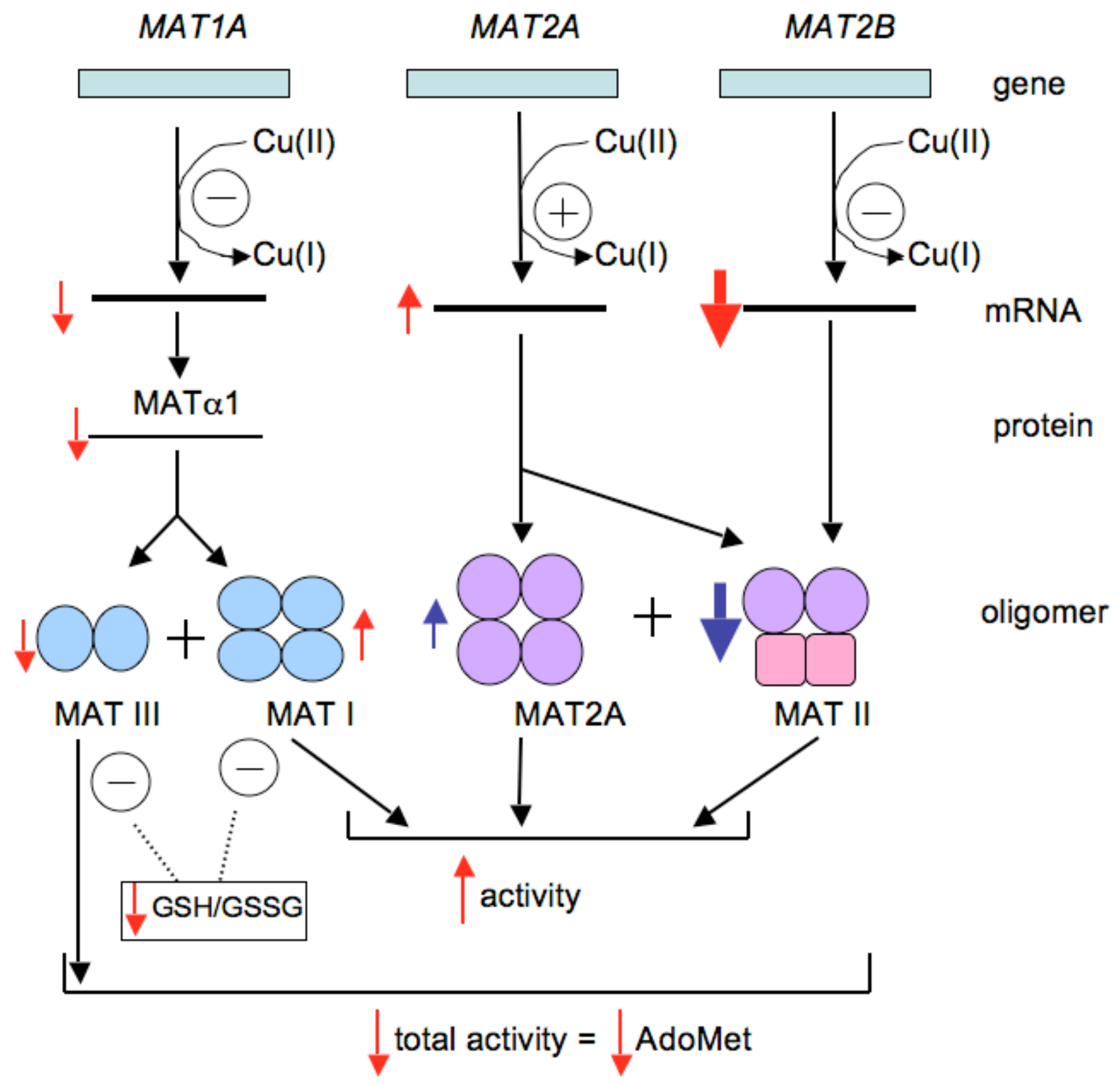


Supplementary material for the manuscript by Delgado el at.

Table 1

Primer sequences used for Quantitative Real Time RT-PCR experiments. Appropriate primers were designed using the Program Primer Express 3.0 and the rat gene sequences available in the data bank with references: NC 005115 (MAT1A), NC 005103 (MAT2A), NC 005109 (MAT2B), NC 005101 (BHMT), NC $005116(M S)$ and NC $005102(S A H H)$. Concentrations of the primers used in the amplifications appear in the right column.

\begin{tabular}{|c|c|c|c|}
\hline & forward & reverse & $\mathbf{n M}$ \\
\hline$M A T 1 A$ & 5'-GCGAGAGCTACTAGAGGTTGTGAA-3' & 5'-AGATCCAAGTCCCTGACAATAACAC-3' & 300 \\
\hline$M A T 2 A$ & 5'-GGAGGGTTCTTGTTCAGGTCTCT-3' & 5'-GGAAAATGGAGATCGACAATGG-3' & 300 \\
\hline$M A T 2 B$ & 5'-GCAATTGCAGACGCCTTCA-3' & '5'-CAGGGCTGTCAGTAATAGGTCGTA-3' & 300 \\
\hline BHMT & 5'-GGAGATCTACATGGCGTGTCT-3' & 5'-CGGCACCTGCTTTTACCAAA-3' & 300 \\
\hline$M S$ & 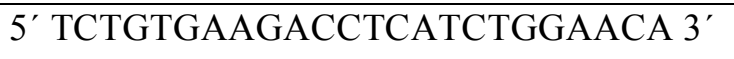 & 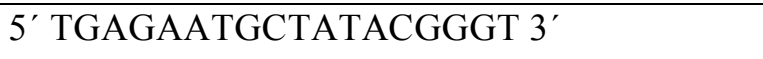 & 300 \\
\hline SAHH & 5' GGGCGGTGACCTTACTAACCTCAT 3' & 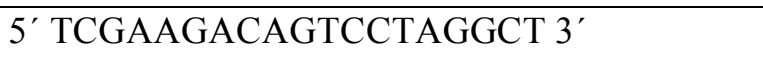 & 300 \\
\hline $18 S$ & 5'-CCAGTAAGTGCGGGTCATAAGC-3' & 5'-CCGATTGGATGGTTTAGTGAGG-3' & 100 \\
\hline
\end{tabular}

